\title{
Dual approach for large submandibular calculi
}

\begin{abstract}
Sialolithiasis is the most common cause of inflammatory disease of large salivary glands and occurs in about $1.2 \%$ of the population. It most often occurs in the submandibular gland $(87 \%)$; followed by the parotid gland - $(10 \%)$ and the sublingual gland - $(3 \%)$. The introduction of minimally invasive surgical procedures has significantly reduced the rate of major salivary gland removal due to sialolithiasis. Sialoendoscopy is the method of choice with a high rate of success and gland preservation in small and medium stones. The combined transoral and endoscopic approach is indicated for large stones in the submandibular gland. In order to stabilise the duct and prevent the formation of a secondary stenosis, it is appropriate to insert a stent. Long term follow up shows that this dual approach surgery can be performed with a high rate of success.
\end{abstract}

Volume 8 Issue 2 - 2017

\author{
Anand V,' Aishwarya Anand, ${ }^{2}$ Manaswini \\ Ramachandra ${ }^{2}$ \\ 'Head of department of ENT MCV ENT Hospital, India \\ ${ }^{2}$ MCV ENT Hospital, India
}

Correspondence: Aishwarya Anand Consultant MCV ENT Hospital I I 5 Palghat road Pollachi Tamilnadum, India,Tel 9994355755,Email aishwaryaanandcmc@yahoo.in

Received: December 26, 2016 | Published: July 24, 2017

Keywords: sialendoscopy, large calculi, mega stone, submandibular gland, transoral approach, sialadenitis

\section{Introduction}

Sialolithiasis is the most common cause of both obstruction and sialadenitis. ${ }^{1}$ The typical presentation is of a painful swelling of the gland at meal times when the gland auto inflates with obstructed saliva.

Sialolithiasis is responsible of $30 \%$ of all salivary pathologies. Some $80 \%$ to $90 \%$ of calculi are found in the submandibular gland ${ }^{2}$. While parotid and sublingual gland have a rate of $10 \%$ and $5 \%$ respectively. Traditionally, the treatment for calculi in the proximal duct or gland has been sialadenectomy. The main rationale determining surgical policy is the widely held view that proximal stones cause permanent structural damage to the gland, which in turn are predisposed to recurrent infection. ${ }^{3}$

Sialadenectomy related morbidity is well known: it's possible early and late postoperative complications include neurologic and aesthetic sequelae and functional impairment. ${ }^{4}$ Furthermore, unilateral submandibular gland excision decreases resting salivary flow and subjective xerostomia..$^{5-7}$

It is widely believed that proximal stones cause permanent structural damage to the gland, thereby pre-disposing the gland to recurrent infection. Thus, proximal stones are generally removed from the sub-mandibular gland using a transcervical approach.

However, there is mounting clinical and experimental evidence that salivary glands can regain useful function after stone removal. ${ }^{5,8}$ Given the above, various minimally invasive and conservative techniques have recently been developed, including extracorporeal lithotripsy, interventional radiology, and operative sialoendoscopy, 9-12each of which have specific indications. Hong et al reported an intraoral removal technique for the submandibular gland with excellent outcomes..$^{13}$ According to therapeutic flow chart, described by Marchal et al., ${ }^{12}$ large salivary stones $(>8 \mathrm{~mm})$ may be removed with combined sialoendoscopic and transoral approach.

The aim of this study is to describe the surgical technique of hilo parenchymal submandibular large stones removal and to assess the functional results after surgery.

\section{Patients and methods}

This prospective study was conducted at MCV ENT hospital, Pollachi, India from April 2013 to April 2016. Our study group comprised 8 consecutive patients who underwent removal of submandibular stones. All of the patients were diagnosed with proximal submandibular stones in the hilum of the submandibular gland by ultrasonography or computed tomography. We defined proximal submandibular stones as stones posterior to the first molar. A single surgeon performed all the surgeries for removal of stones. None of the patients had a prior history of stone-removal surgery, and all patients had normal lingual nerve and hypoglossal function prior to surgery.

\section{Surgical procedure}

The procedure was performed under local anaesthesia after premedication. Mouth opening was ensured by mouth opener. Wharton's duct was identified and cannulated using increasing diameter salivary probes. Local anaesthetic solution instilled into the duct. It was enlarged until placing sialoendoscope. A traditional sialoendoscopy was performed in order to view the stone. Exploiting sialoendoscopic view, transillumination of the floor of mouth and bimanual palpation, the exact location of the stone was detected. Afterwards, the tongue was retracted antero-medially and the gingivolingual sulcus was infiltrated with a solution composed by anaesthetic and vasoconstrictor agent just on the site detected by transillumination. After sialoendoscopy, a guide wire was positioned inside the duct to allow the identification of the duct. With the help of a loupe, a deep incision of the floor of mouth in gingivolabial sulcus adjacent to the molars as performed, corresponding to the proximal third of Wharton's duct and submandibular hilum (Figure 1).

Blunt dissection was performed until the lingual nerve and Wharton's duct were identified. At this level, lingual nerve appears as a white string located laterally to the Wharton duct. The lingual nerve was isolated and preserved. The glandular hilum was moved upward by an external finger pressure of submandibular gland (Figure 2).

The surgeon proceeded with dissection until parenchymal gland viewing. In order to reach and remove the stone, an incision of glandular parenchyma was performed as much medial to the glandular hilum as possible. The dissection proceeded until the viewing of the stone site. The stone was removed using a curved artery forceps (Figure 3). The stones in the proximal part of duct were removed by incising the duct. The incision made in the duct was closed with 4-0 absorbable sutures. After stone removal, a second sialoendoscopy was performed in order to check for any residual intraparenchymal calculi 
and duct was irrigated with antibiotic and steroid solution. A sialostent was positioned under sialoendoscopic viewing from the distal to the proximal portion of the duct and it was left in place for at least 3 weeks. Finally, the oral floor wound was sutured with resorbable stitch. All patients were discharged 1day after surgery and received antibiotic therapy and steroid for 1 week.

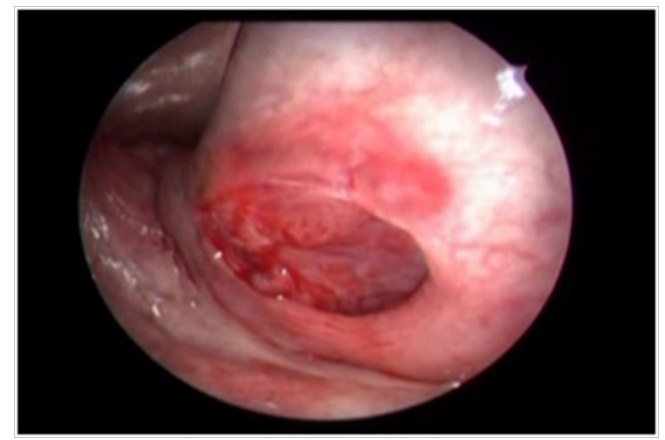

Figure I Showing the incision made in the gingivo-labial sulcus adjacent to the molars.

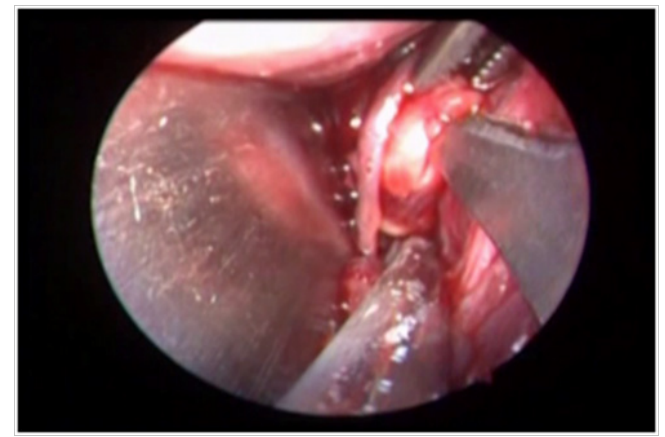

Figure $\mathbf{2}$ Showing the relationship of lingual nerve to the Wharton's duct and the incision being made near the hilum of.

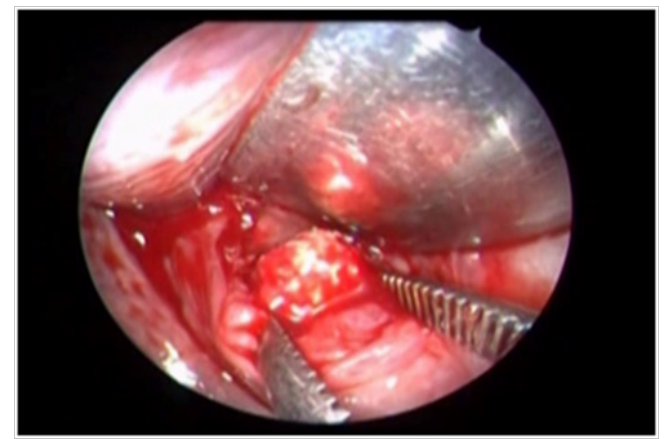

Figure 3 Showing the incision on the glandular parenchyma and the stone being removed with a curved artery forceps.

\section{Results}

Stones removal was performed in all cases except in one patient The average size was $14 \mathrm{~mm}$ diameter, ranged between $10 \mathrm{~mm}$ and $18 \mathrm{~mm}$. The stones were located in right submandibular gland in 3 cases and in left submandibular gland in 5 cases. Lingual nerve and hypoglossal nerves were preserved in all cases. No intraoperative complications were observed. Early complications, consisting of transitory swelling in 3 cases $(37.5 \%)$ and temporary lingual nerve paraesthesia in 1 patient $(12.5 \%)$. No infective com-plications were detected. Post-operatively patients were followed up for 18 months. No long-term complications occurred. One month after surgery all patients underwent repeat ultrasound assessment and 1 of the patients showed residual sialolithiasis. He underwent sialadenectomy as the calculus (size $1.6 * 1 \mathrm{~cm}$ ) was intraglandular .Mean surgical time was 71.5 minutes.

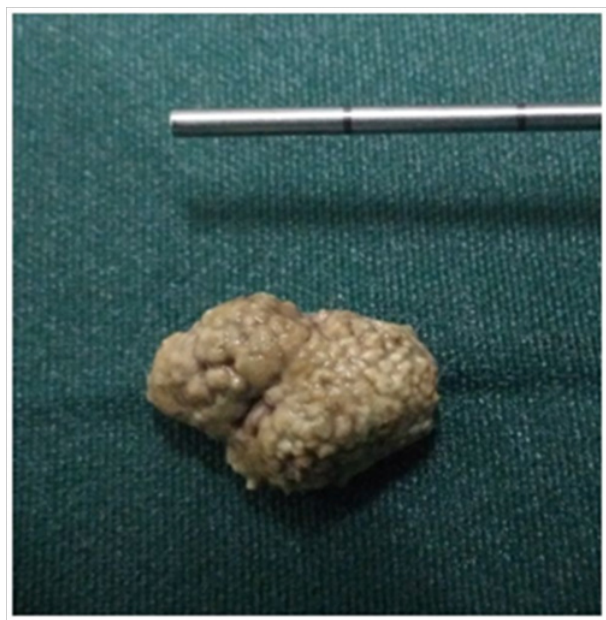

Figure 4 Showing picture of the megastone removed by dual approach.

\section{Discussion}

The most common cause of acute and chronic infections of salivary glands is due to sialolithiasis. ${ }^{14,15} 80-90 \%$ of calculi are found in the submandibular gland. ${ }^{16}$ The average growth rate of these calculi are $1-1.5 \mathrm{~mm} /$ year and the average size range is $0.1-30 \mathrm{~mm} .{ }^{17,18}$

These salivary calculi consist mainly of calcium phosphate and hydroxyapatite and small amounts of magnesium, potassium and ammonia. ${ }^{16,19}$ Calculi formation occurs from the deposition of calcium salts around an organic nidus which consists of altered salivary mucins, bacteria and desquamated epithelial cells..$^{20,21}$ Submandibular calculi are $82 \%$ inorganic and $18 \%$ organic and are formed from a nidus of mu-cous. ${ }^{3,22,23}$ Theories have been put forth for the occurrence of this phenomenon - (a) occurs in two phases: central core and layered periphery, ${ }^{24}$ (b) precipitation of calcium and phosphate ions occur due to a metabolic phenomenon which increases the salivary bicarbonate content, ${ }^{19,25}$ (c) retrograde theory - aliments, substances, bacteria migrate from oral cavity into salivary ducts thus forming a nidus. ${ }^{24}$ Subman-dibular gland is more prone to calculi formation as the salivary content is more alkaline, has high calcium and phosphate concentration and a higher mucous content. ${ }^{26,27}$ Also, Wharton's duct is longer and the gland has an antigravity flow. ${ }^{26}$

Most common presentation is an increase in size and pain on intake of food ("mealtime syndrome"). 8,28 These symptoms are caused due to stasis of saliva causing bacterial ascent into the gland parenchyma. ${ }^{19}$ Calculi obstruction for prolonged periods causes gland atrophy, followed by lack of secretory function and fibrosis. ${ }^{19}$

The investigations done are ultrasound, CT Scan and/or sialography. ${ }^{19,29}$ The latter is useful in radiolucent stones and those that are deep seated. Sialography is contraindicated in patients with an acute infection and in those who have an allergy to contrast. ${ }^{19}$ $40 \%$ of parotid and $20 \%$ of submandibular calculi are radiolucent, necessitating sialography. ${ }^{20}$

Taking into consideration the size of calculi, if small, conservative line of management can be tried - in-creased hydration, gland massage while using sialogogues, moist warm heat application and antibiotics in presence of infection. ${ }^{19}$ 
Up until now, sialadenectomy was the treatment of choice for salivary calculi removal. The risks of surgery were overlooked owing to lack of other techniques and also importantly the assumption that calculi blocking the duct caused an irreversible damage to the functioning of the gland. ${ }^{17}$

Minimally invasive techniques have now gained precedence owing to reduced morbidity, retaining a functional gland after removal of calculi and the procedure being day-care and performed under local anaesthesia. ${ }^{7,8}$ More than $70 \%$ of calculi can be retrieved using these techniques, and $2 \%$ unsuccessful cases will require a sialadenectomy. ${ }^{8}$ Endoscopy, is used for calculi removal and as a diagnostic tool..$^{30}$ Endoscopic basket and microforceps usage for calculus removal was used when the calculus was mobile and was no more than twice the diameter of the duct ( $<5 \mathrm{~mm}$ normally) ${ }^{31}$ Extracorporeal lithotripsy is more effective in parotid than in submandibular gland. ${ }^{29}$ The choice of treatment for deeply seated submandibular calculi which are fixed to the duct wall is an intraoral removal. The only exclusion for this procedure is when the stone cannot be palpated intraorally. ${ }^{8}$

In the study by Makdissi et al., ${ }^{14}$ the affected glands showed improvement after removal of calculus, though they had reduced function in comparison to the unaffected glands. Scintigraphic analysis in a study by Yoshimura ${ }^{7}$ showed that the recovery of the function of the gland post removal of calculus was inversely proportional to the size of the stone. Intraoral removal of submandibular calculi was successful in $95.8 \%$ cases in the study by M.McGurk et al., ${ }^{8}$ In the rest of the cases sialadenectomy was done following intraoral surgical failure.

The acceptance and success of minimally invasive techniques is due to the miniaturisation of instruments - microendoscopes, forceps and lithotripters and a change in the surgical prospective leaning toward the preservation of gland owing to studies which prove recovery of function following removal of calculi. ${ }^{29}$

\section{Conclusion}

The outcomes of this preliminary study suggest that combined sialoendoscopic and transoral approach is a feasible, safe and effective technique for treatment of large hiloparenchymal sub-mandibular stones; it may performed as a day care procedure. It also reduces mean operation time and post-operative sequelae. We therefore recommend that our dual approach method replace submandibular resection as the primary procedure for the removal of proximal submandibular stones. Future studies with longer follow-up will confirm the risk for recurrence of calculi.

\section{Acknowledgments}

None.

\section{Conflicts of interest}

Author declaers there are no conflicts of interest.

\section{Funding}

None.

\section{References}

1. Ngu RK, Brown JE, Whaites EJ, et al. Salivary duct strictures: nature and incidence in benign salivary obstruction. Dentomaxillofacial Radiol. 2007;36(2):636-637.

2. Lustmann J, Regev E, Melamed Y. Sialolithiasis. A survey on 245 patients and a review of the literature. Int J Oral Maxillofac Surg. 1990;19(3):135-138.

3. Bates D, O'Brien CJ, Tikaram K, et al. Parotid and sub-mandibular sialadenitis treated by salivary gland excision. Aust $N$ Z J Surg. 1998;68(2):120-124.

4. Berini-Aytes L, Gay-Escoda C. Morbidity associated with re- moval of submandibular gland. J Craniomaxillofac Surg. 1992;20(5):216-219.

5. Van den Akker H, Busemann-Sokole E. Submandibular gland function following transoral sialolithectomy. Oral Surg. 1983;56(4):351-356.

6. Novotny GM. Submandibular sialolithiasis: transoral excision. $J$ Otolaryngol. 1989;18(7):354-356.

7. Yoshimura Y, Morishita T, Sugihara T. Salivary gland func- tion after sialolithiasis: scintigraphic examination of submandibular glands with 99mTc-Pertechnetate. J Oral Maxillofac Surg. 1989;47(7):704-710.

8. McGurk M, Escudier MP, Brown JE. Modern management of salivary calculi.Br J Surg. 2005;92(1):107-112.

9. Zenk J, Bozzato A, Winter M, et al. Extracorporeal shock wave lithotripsy of submandibular stones: evaluation after 10 years. Ann Otol Rhinol Laryngol. 2004;113(5):378-383.

10. Drage NA, Brown JE, Escudier MP, et al. Interventional radiology in the removal of salivary calculi. Radiology. 2000;214(1):139-142.

11. Nahlieli O, Baruchin AM. Long term experience with endoscopic diagnosis and treatment of salivary gland inflam- matory disease. Laryngoscope. 2000;110(6):988-993.

12. Marchal F, Dulguerov P, Becker M, et al. Specificity of parotid sialendoscopy. Laryngoscope. 2001;111(2):264-271.

13. Hong KH, Kim YK. Intraoral removal of the submandibular gland: a new surgical approach. Otolaryngol Head Neck Surg. 2000;122(6):798-802.

14. Makdissi J, Escudier MP, Brown JE, et al. Glandular function after intraoral removal of salivary calculi from the hilum of the submandibular gland British Journal of Oral and Maxillofacial Surgery. 2004;42(6):538-541.

15. Epker BN. Obstructive and inflammatory diseases of the major salivary glands. Oral Surg Oral Med Oral Pathol. 1972;33(1):2-27.

16. Bodner L. Salivary gland calculi: diagnostic imaging and surgical management. Compendium. 1993;14(5):572-586.

17. Norman JEB, McGurk M. Color atlas and text of the salivary glands diseases, disorders and surgery. Mosby Wolfe, Barcelona, Spain. 1995.

18. Frame JW, Smith AJ. Large calculi of the submandibular salivary glands. J Oral Maxillofac Surg. 1986;15:769-771.

19. Williams MF. Sialolithisis. Otolaryngologic Clinics of North America. 1999;32(5):819-834.

20. Cawson RA, Odell EW. Essentials of oral pathology and oral medicine. (6th edn), Edinburgh: Churchill Livingstone, UK. 1998. p.239-240.

21. Carr S J. Sialolith of unusual size and configuration. Oral Surg Oral Med Oral Pathol . 1965;20(6):709-712.

22. Zenk J, Benzel W, Iro H. New modalities in the management of human sialolithiasis. Minimally invasive therapy. 1994;3(5):275-284.

23. Pollack CV, Severance HW. Sialolithisis: case studies and review. $J$ Emergency Medicine. 1990;8(5):561-565.

24. Marchul F, Kurt AM, Dulguerov P, et al. Retrograde Theory in sialolithiasis formation. Archives of Otolaryngology- Head and Neck Surgery. 2001;127(1):66-68.

25. Blatt I. Studies in sialolithiasis: III. Pathogenesis, diagnosis, and treatment. South Med J. 1964;57:723-728. 
26. Leung A K, Choi M C, Wagner GA. Multiple sialolths and a sialolith of unusual size in the submandibular duct. Oral Surg Oral Med Oral Path Oral Radiol Endo. 1999; 87(3): 331-333.

27. Zakaria MA. Giant calculi of the submandibular salivary gland. $\mathrm{Br} J$ Oral Surg. 1981;19:230-232.

28. Hardy KJ. Submandibular calculus disease at the Royal Melbourne Hospital. Med J Aust. 1966;16:670-671.

29. Iro H, Zenk J, Escudier MP, et al. Outcome of Minimally Invasive Management of Salivary Calculi in 4,691 Patients. The Laryngoscope. 2009;119(2):263-273
30. Steiner M, Gould A R, Kushner G M, et al. Sialolithiasis of the submandibular gland in an 8year-old child. Oral Surg, Oral Med, Oral Pathol, Oral Radiol, Endod. 1997;83(2):188.

31. Nahlieli O, Shacham R, Bar T, et al. Endoscopic mechanical retrieval of sialoliths. Oral Surg Oral Med Oral Pathol Oral Radiol Endod. 2003;95(4):396-402. 